\title{
Edgar A. Poe y las artes: el ideario artístico sugerido a través de "The Assignation"
}

Alejandro Jaquero Esparcia

Universidad de Castilla-La Mancha (España) 



\title{
Edgar A. Poe y las artes: el ideario artístico sugerido a través de "The Assignation"
}

\section{Edgar A. Poe and the Arts: the Artistic Ideology Suggested through "The Assignation"}

\author{
Alejandro Jaquero Esparcia \\ Universidad de Castilla-La Mancha (España) \\ alejandro.jaquero@uclm.es
}

Fecha de recepción: 02 de septiembre de 2019

Fecha de aceptación: 18 de noviembre de 2020

\section{Resumen}

El legado literario de Edgar Allan Poe ha sido asociado por la cultura popular, más que por la historiografía, al mundo gótico y la escritura de terror. No obstante, muchos estudios actuales inciden en la amplitud de temáticas presentes en la obra del escritor bostoniano. Ello se debe en parte a la formación adquirida como revisor literario en prensa y la satisfacción por instruirse, tanto de los sucesos histórico-artísticos europeos y orientales como los novedosos progresos científicos desarrollados durante el siglo XIX. En este sentido, las referencias al mundo de las artes figurativas y arquitectónicas son constantes en su obra, configurando en algunos casos la acción misma de sus narraciones. Pretendemos examinar cómo, desde un lenguaje cuidado y experto, sugiere al lector una imagen del coleccionista ideal y de sus criterios estéticos a lo largo del cuento "La cita".

Palabras clave: Edgar Allan Poe; Historia del Arte; La cita; Coleccionismo artístico; Siglo XIX

\footnotetext{
Abstract

The literary legacy of Edgar Allan Poe has been identified by the popular culture, rather than the historiography, as belonging to the Gothic universe and the horror tales. However, many current studies have noted the variety of topics present in the work of the Bostonian. This is partly due to the training acquired as a literary reviewer when working in several journals and newspapers, and his interest for being well informed about European and Eastern historical and artistic facts and the pioneering scientific discoveries of the 19th century. In this sense, the references
} 
Edgar A. Poe y las artes: el ideario artístico sugerido...-A. Jaquero Esparcia

to the Fine Arts are constant in his work, being in some cases the very core of his narrations. We intend to examine how, with a careful and expert language, he presents the reader a picture of the ideal collector and his aesthetic principles throughout the tale "The Assignation."

Keywords: Edgar Allan Poe; Art History; The Assignation; Artistic Collecting; $19^{\text {th }}$ Century

\section{INTRODUCGIÓN}

Las investigaciones interdisciplinares sobre la figura de Edgar Allan Poe producidas durante los últimos años nos han ofrecido una renovada visión del alcance logrado por su narrativa en diferentes campos de las artes y las ciencias ${ }^{1}$. Desde ámbitos propios de la Historia de la Literatura, Filología Moderna o de la Historia del Arte se han generado trabajos que han señalado su especial relación con las artes visuales y la proyección de estas manifestaciones artísticas en su obra escrita; un buen ejemplo de ello lo hallamos examinando los diferentes artículos publicados en estos últimos años sobre el tema en las publicaciones académicas The Edgar Allan Poe Review o Poe Studies ${ }^{2}$. De algún modo, en la raíz de muchas de estas revisiones de la obra poeniana emerge una realidad concreta: la aproximación del autor a la figura clásica europea del literato-pintor o pintor-poeta, heredera de la tradición clásica del ut pictura poesis (Hagstrum, 1958, pp. 3-36). Aunque desde unos postulados estéticos románticos, la idea de este perfil creador artístico-literario no es nueva, ya que se venía consolidando desde períodos anteriores; es por ello por lo que podríamos englobar la trayectoria de Poe en la tradición de autores como Dante, Cervantes o Shakespeare, por citar algunos paradigmas de la literatura universal (Levi, 2010, pp. 235-237; De Armas, 2006, 14-112; Thorp, 1931, pp. 672-693).

En el siguiente artículo se expone un caso claro de cómo el legado literario de Poe se encuentra sustentado en la herencia de la literatura artística de su tiempo, utilizando para dicho fin escritos sobre las artes, opúsculos estéticos, diccionarios artísticos o críticas de arte vertidas en prensa. Una lectura detenida de su producción literaria sostiene estos razonamientos, ya que empleó con frecuencia conceptos relacionados con el mundo artístico. De hecho, algunas de dichas ideas están por encima de un simple conocimiento superficial de aficionado. El caudal visual

1 Este trabajo forma parte de las actividades derivadas del Proyecto de Investigación Regional "Edgar Allan Poe en España en la primera mitad del siglo XX: recepción, ediciones e ilustradores" (DIPUAB-2020-4) cofinanciado por la Universidad de Castilla-La Mancha y la Diputación de Albacete. Queremos agradecer a los profesores Fernando González Moreno y Margarita Rigal Aragón el apoyo y las sugerentes indicaciones que nos han aportado para construir la definitiva versión de este estudio.

2 De entre los artículos dedicados en ambas publicaciones a Edgar A. Poe y las Bellas Artes señalamos (Saltz, 2006, pp. 4-30; Pahl, 2006, pp. 30-49; Savoye, 2013, pp. 233-234; Moreland y Rodríguez, 2015, pp. 204-220; Miyazawa, 2017, pp. 88-106 y González Moreno y Rigal Aragón, 2018, pp. 7-27). 
del autor, asimismo, no se limitó a las obras que conoció a través de sus colegas artistas en los Estados Unidos, sino que también tuvo la oportunidad de construir un pensamiento artístico mediante el uso de fuentes gráficas, especialmente estampas sueltas o ilustraciones de diversos libros vinculados a las artes. Publicaciones como la de la profesora Cantalupo han puesto de relieve dichas conexiones, focalizando la importancia de estos nexos artístico-literarios en los vínculos mantenidos con artistas de la época o las preferencias del autor por los artistas clásicos, resultado de la contemplación de algunas de estas obras en Estados Unidos y durante su estancia juvenil en Inglaterra, en especial la preferencia por el pintor napolitano Salvatore Rosa (Cantalupo, 2014, pp. 20-23).

Partiendo del estado de la cuestión que nos precede y desde un enfoque interdisciplinar, analizaremos uno de los cuentos del autor donde se observa la importancia de los elementos provenientes de las Bellas Artes en el transcurso de la narración; en concreto, el cuento "The Assignation", traducido por Julio Cortázar como "La Cita". Mediante una relectura pormenorizada en la que se atiende con mayor atención a estos matices estéticos e histórico-artísticos podremos acercarnos a las conexiones del autor con el ideario artístico del período en que vivió.

\section{EDGAR ALLAN POE Y LA TEORÍA DE LAS ARTES DEL SIGLO XIX EN EUROPA Y NORTEAMÉRICA}

Antes de centrarnos en el texto, se presenta necesario exponer un panorama de la realidad teórica desarrollada en aquellos años y de las principales corrientes estéticas dominantes. Durante el siglo XIX el legado teórico-artístico generado a finales de la anterior centuria estuvo muy presente en la confección de las ideas estéticas que se buscan perpetuar, aunque también transgredir (Barasch, 2002, pp. 146-149). Además, la influencia del pensamiento europeo en los focos artísticos norteamericanos fue más que palpable, debido muchas veces a la herencia de esta literatura recibida desde grandes centros culturales localizados en Inglaterra o Francia, unido también a la reedición de textos clásicos del pensamiento estético del Viejo Mundo ya en el propio territorio americano con la idea de suministrar al incipiente mundo académico (Groseclose, 2000, pp. 8-13; Pevsner, 1982, pp. 104109).

Durante el siglo XVIII y comienzos del XIX tiene su culminación el establecimiento de la estética como disciplina emanada del ámbito filosófico. Con la llegada del Romanticismo se debatirá nuevamente de ciertos temas como el de la Belleza o lo Sublime, y surgirán nuevas categorías estéticas como el Pintoresquismo, de tanta profusión para el mundo artístico y literario (Ashfield y Bolla, 1996, pp. 1-16; González Moreno, 2007, pp. 38-62; Vozal, 2011, I, pp. 19-31). La concepción del espacio pintoresco y, por ende, romántico, tiene en estos razonamientos teóricos las bases que el propio Poe aplicaría en la composición de sus cuentos relacionados con el 
Edgar A. Poe y las artes: el ideario artístico sugerido...-A. Jaquero Esparcia

paisaje y la naturaleza, y también en su poesía (Rodríguez Guerrero-Strachan, 2010, 97-106). Una revalorización del paisaje no alterado por el ser humano y conservado en estado natural y salvaje. No obstante, estas ideas que han sido contrastadas por la investigación dentro de su obra tuvieron que ser adquiridas a través de la lectura de ensayos filosóficos o textos derivados de diferentes ejemplos de la literatura artística.

Con el fin de presentar las bases de estos escritos artísticos resulta fundamental partir de las reflexiones paradigmáticas sobre la concepción del arte y las ideas estéticas de Johann Winckelmann, cuya obra culmen Geschichte der Kunst des Alterthums (Historia del Arte de la Antigüedad, 1764) fue reeditada con asiduidad y traducida a varios idiomas. Así se lograba trasladar una nueva interpretación sobre la estima por el arte de los antiguos, consolidando una mirada afectiva hacia el arte de los griegos y construyendo las bases del pensamiento neoclásico, corriente artística que debía sustentar los cimientos de una sociedad más culta, justa y mejor (Barrell, 1986, pp. 258-307). La renovada manera con la que valorar y juzgar el objeto artístico, junto a las ideas promulgadas por otros pensadores como Anton Raphael Mengs en total sintonía con el anterior, tuvieron una clara influencia en la literatura finisecular europea sobre el arte y el pensamiento artístico del siglo XVIII.

El constructo estético concebido dentro del ámbito neoclásico propuesto por Centroeuropa, pero nacido de una fuerte tradición grecolatina, fue incluyéndose en las reflexiones de los artistas y escritores ingleses del momento como William Blake, Sir Joshua Reynolds o Henry Fuseli. De esta forma, el propio Fuseli tradujo y editó algunos de los textos de Winckelmann, sirviéndonos de ejemplo la versión de los Gedanken über die Nachahmung der griechischen Werke in der Malerei und Bildhauerkunst (1756), adaptado con el título de Reflections on the Painting and Sculpture of the Greeks (1765). El traductor se posicionaba junto a los postulados del esteta alemán, además de expresar su ideario crítico sobre el arte manifestando una consolidada admiración por la nueva forma de observar a los clásicos (Fried, 1986, pp. 87-97; Antal, 1989, pp. 49-57). Del mismo modo, las reflexiones de Mengs ya habían inspirado a escritores como Daniel Webb en Inglaterra. Su tratado Gedanken über die Schönheit und über den Geschmak in der Malerey fue publicado en Zúrich en 1762, con la particularidad de haber colaborado en su edición Henry Fuseli y su padre Johann Caspar Fuseli (Pelzel, 1976, pp. 412-413). A finales de siglo llegaría a publicarse en lengua inglesa la edición de sus escritos, elaborada por el ministro español José Nicolás de Azara, The Works of Anthony Raphael Mengs, First Painter to his Catholic Majesty Charles III (1796), traducida al inglés por el Revd. Robert Darley Waddilove; de este modo se hacía accesible el ideario neoclásico de Mengs al público y los artífices ingleses ${ }^{3}$. Una prolongada tarea de traducciones y reediciones generadas en el ámbito anglosajón que tuvieron una conexión directa con los primigenios ambientes academicistas norteamericanos, llegando muchas de

3 Citamos la información a partir del estudio introductorio a la edición facsímil y española del texto (Mengs, 1989, pp. 21 y 31). 
estas obras a conocerse y manejarse en el Nuevo Mundo. Un ambiente, asimismo, común a las inquietudes culturales de Poe.

La primera mitad del siglo XIX recupera toda una tradición de investigación histórica y enciclopédica que tuvo su reflejo en la publicación de grandes recopilatorios de erudición, donde se deben mencionar los trabajos específicos destinados a la Historia del Arte. Estos diccionarios supusieron una herramienta de gran valor para el conocimiento biográfico de las vidas de artistas, su producción artística y sus diferentes trayectorias, permitiendo a personas con ciertas inquietudes culturales adquirir un bagaje mínimo sobre las Bellas Artes. Sirva de ejemplo el manual de Matthew Pilkington, The Gentleman's and Connoisseur's Dictionary of Painters (1770) obra dedicada al caballero o connoisseur que buscaba adquirir un juicio medio sobre temas de tipo científico y humanístico. Esta publicación, deudora de los ideales renacentistas promulgados por Castiglione en su Il Cortigiano -texto manejado por Poe-y otros tratados ingleses como el The Complete Gentleman (1622) de Henry Peacham, fue aumentada y reeditada a lo largo de la centuria posterior y sirvió al lector para acercarlo de manera ordenada y concisa a las noticias sobre el arte y los artistas (Houghton, 1942, pp.190-219; Salerno, 1951, pp. 234-258).

La prensa y las revistas decimonónicas también fueron fuentes teóricas y gráficas de gran valor para conformar una personalidad artística, recursos a los que Poe tuvo acceso preciso, confirmándose su participación en la edición de algunas de ellas. Las noticias recogidas en el o en el American Museum of Science, Literature an the Arts (1838) o en el Broadway Journal (1845-46) -periódico del que, durante su corta existencia, Poe llegó a ser principal editor y propietario- son una buena muestra de ello. Recursos narrativos en los que se hallan críticas artísticas o reseñas sobre obras de arte de diversos lugares, permitiendo acceder a un conocimiento elemental, y en algunos casos algo más especializado. Fueron, en cierto sentido, las nuevas plataformas donde se desarrolló la Historia del Arte del siglo XIX y XX. Un proceso, también en este caso, iniciado en algunos de los países europeos que fueron referentes artísticos en este siglo, como Inglaterra, Francia y de alguna forma también España (Solkin, 2001; Démoris y Ferran, 2001; Crespo Delgado, 2015, pp. 199-215).

Ahora bien, si queremos aportar un marco más definido del perfil de Poe como lector y de cómo a través de él adquirió una sólida formación artística debemos recopilar datos en torno a las bibliotecas y centros académicos con los que estableció contactos. Gracias a las investigaciones de Campbell y Griggs somos conscientes de la realidad bibliográfica que manejó el escritor bostoniano: la lectura de prensa -con abundantes críticas artísticas y recensiones sobre literatura artística europea-, revistas literarias, diccionarios y enciclopedias generales, textos clásicos grecolatinos, poesía y narrativa contemporánea, ensayos filosóficos, estudios históricos, literatura de viajes o ensayos científicos (Campbell, 1925, 166-196; Griggs, 1929, pp. 196-199) ${ }^{4}$.

4 González-Rivas añade en una de las notas de su trabajo sobre Poe y "The Assignation" un interesante repaso sobre esta bibliografía utilizada (2009, p. 61). 
Edgar A. Poe y las artes: el ideario artístico sugerido...-A. Jaquero Esparcia

Algunos de los textos son recursos elementales para la transmisión de ideas estéticas e histórico-artísticas. No resultaría descabellado, además, que hubiese consultado, revisado o leído fragmentariamente obras más específicas del campo de la literatura artística. De hecho, Poe pudo acceder a través de su puesto de revisor literario y la amistad con varios artistas norteamericanos a las bibliotecas de instituciones académicas, las cuales albergaban, sobre todo, tratados teóricos y diccionarios sobre las artes y sus principales figuras. Un buen ejemplo de dichos intercambios culturales lo tenemos en el caso de la universidad jesuítica de Fordham, debido a la amistad que mantuvo con el reverendo Edward Doucet; su contacto con el eclesiástico le permitió acceder a un ámbito académico de alto nivel, desde el cual pudo consultar la estupenda biblioteca universitaria. En ella se albergaban textos sobre Winckelmann, Stefano Raffei, Mengs, Fuseli y otros teóricos y estetas europeos del XIX (Quinn, 1998, pp. 520-521).

De igual modo, las bibliotecas de las academias de arte disponibles en los círculos culturales frecuentados por Poe albergaron estas publicaciones; instituciones que eran deudoras la tradición literario-artística europea (Duro, 2002, pp. 88-103). Por ejemplo, sabemos que en la Academia de Bellas Artes de Pennsylvania se encontraban tomos de la Storia pittorica della Italia. Dal risorgimento delle belle arti fin presso al fine del XVIII secolo (1809) de Luigi Lanzi, en concreto la edición de Thomas Roscoe de 1847 publicada en Londres, elaborada a partir de la primera traducción de $1828^{5}$. También se contaba con libros como el de A O'Neil A Dictionary of Spanish Painters: Comprehending that Part of their Biography Immediately Connected with the Arts, from the Fourteenth Century to the Eighteenth (1833-34), algunos de los textos ya citados de Winckelmann y, en definitiva, un compendio del saber artístico europeo básico para comprender la estética neoclásica y romántica.

Bajo estas premisas presentamos el reflejo de la cultura teórico-artística europea en el incipiente ideario académico norteamericano. Sería arriesgado afirmar rotundamente que Poe haya manejado toda esta ingente información; sin embargo, una correcta exégesis de su obra, como ya se ha realizado por algunos investigadores como Mabbot, Pollin, Cantalupo o Rigal Aragón, nos demuestran que el autor bostoniano conocía aspectos sobre las artes que solamente podían ser adquiridos a través de la lectura de obras relevantes de estética y de literatura artística. Edgar A. Poe no pudo permanecer ajeno a las diferentes ideas estéticas o la crítica de arte vertida en prensa durante su tiempo debido sobre todo a su formación cultural y, en especial, laboral, que le obligaba a leer innumerables tipos y variedades de géneros, ensayos y demás modelos literarios; unido todo ello a sus demostradas inquietudes sobre las Bellas Artes, que serán objeto principal de este estudio.

5 El título concreto es The History of Painting in Italy, from the Period of the Revival of the Fine Arts to the End of the Eighteenth Century, publicado en Londres en 1847. 


\section{CONSIDERACIONES TEÓRICO-ARTÍSTICAS Y VISUALES EN "LA CITA"}

"The Visionary" fue publicado por vez primera en 1834; renombrado en el año 1845 por el propio autor con el título "The Assignation" y conocido en español como "La cita". La acción narrativa fue establecida en Venecia, introduciéndonos en un marco artístico sugerente condicionado por el espíritu del Romanticismo (Poe, 1978, II, p. 149) ${ }^{6}$. El uso de la ciudad de Venecia como motivo y espacio literario fue utilizado con fines similares a los de Poe por otros autores románticos como Byron, Wordsworth, Mary Wollstonecraft Shelley o Percy Bysshe Shelley (Perosa, 1999, pp. 115-128). El texto ha sido, asimismo, estudiado y comentado por multitud de investigadores, por lo que se ha generado una rica y abundante bibliografía acerca del mismo ${ }^{7}$. No obstante, los análisis que destacan las manifestaciones artísticas de la obra no son tan prolíficos. Junto a las notables referencias propuestas en el aparato paratextual del texto por Thomas O. Mabbot, un muy buen ejemplo es el de la profesora González-Rivas Fernández. En su estudio nos ofrece la particular relación con la cultura clásica grecolatina existente en la obra, en especial a nivel literario, además de añadir interesantes detalles sobre las referencias artísticas (2009, pp. 50-62). Resulta necesario, por lo tanto, considerar una exégesis específica del cuento atendiendo a los comentarios e ideas derivadas del mundo artístico.

En primer lugar, hemos de iniciar esta relectura introduciéndonos en el estudio de la rica atmósfera creada por Poe haciendo uso de la ornamentación arquitectónica. Atendemos, a continuación, a una serie fragmentos seleccionados justo al comienzo de la creación espacial del urbanismo veneciano:

[...] thine own Venice - which is a star-beloved Elysium of the sea, and the wide windows of whose Palladian palaces look down with a deep and bitter meaning upon the secrets of her silent waters [...] It was at Venice, beneath the covered archway there called the Ponte di Sospiri, that I met for the third or fourth time the person of whom I speak. [...] It was a night of unusual gloom. The great clock of the Piazza had sounded the fifth hour of the Italian evening. The square of the Campanile lay silent

6 La profesora Rigal Aragón indica en su edición de los cuentos que podrían señalarse como posibles influencias del texto El Vicario de Wakefield (1766), de Oliver Goldsmith, Los misterios de Udolpho (1794), de Ann Radcliff e Itinerario de París a Jerusalén (1811), de François-René de Chateaubriand (Poe, 2013, p. 995).

7 Superaría los límites de este artículo el abordar los estudios de todos aquellos investigadores que han profundizado en las complejidades de "The Assignation", cuyas reflexiones continúan siendo publicadas en diferentes ámbitos de la comunidad científica, por lo que limitamos esta nota a las aportaciones más relevantes (Benton, 1963, pp. 193-197; Pitcher, 1980, pp. 1-4; Pahl, 1984, pp. 211229 y Mongtgomery, 2010, pp. 4-28. 
Edgar A. Poe y las artes: el ideario artístico sugerido...-A. Jaquero Esparcia

and deserted, and the lights in the old Ducal Palace were dying fast away (1978, II, pp. $150-151)^{8}$.

Las pocas líneas del escritor bostoniano esbozan una idealizada visión de la ciudad italiana. Ahora bien, para crear esta ambientación neoclásica se ve obligado a alterar la realidad. Lo primero que advertimos es la referencia al legado de Andrea Palladio. La mención al arquitecto renacentista transmite un sentimiento de veneración por la Antigüedad; de hecho, durante los siglos XVIII y XIX fue recuperado por su formalismo clasicista, cuyas características artísticas tanto gustaron en Inglaterra y en la nueva arquitectura norteamericana decimonónica (Pierson, 1970, pp. 290314). Sin embargo, esas visiones palaciegas se pueden relacionar más con Vicenza que con Venecia. La idea del autor no está mal planteada, puesto que no podemos pasar por alto que la teoría palladiana arraiga en la tradición teórica de Vitrubio y la observación metódica de las antigüedades romanas, que finalmente se materializaría en otros proyectos venecianos (D’Evelin, 2012). La interpretación dada por Poe pretende aproximarnos a una visión intencionada de la arquitectura de Venecia a la manera clásica, para lo que acude a ejemplos monumentales notables: la visión del Palazzo Ducale -espacio en el cual también trabajó Paladio-, el gran reloj de la plaza y el Ponte dei Sospiri, todo ellos elementos arquitectónicos reseñables que buscan enfatizar la rememoración grecolatina alrededor de la plaza de San Marcos, pero partiendo de monumentos pertenecientes al medievo o al barroco. Por lo tanto, el escenario idealizado por Poe busca introducir al lector en una visión evocadora de un clasicismo de gran pureza, entroncado con el ideario estético propuesto por Winckelmann; no obstante, la visión romántica del autor termina estando más próxima a una de las vedute venecianas elaboradas por Canaletto, cuyas pinturas y grabados se manejaron con facilidad en el territorio norteamericano (Watson, 1950, pp. 290-293; Beddington y Bradley, 2010). De igual modo, resulta interesante la clara intención del autor a la hora de construir un arquetipo de espacio clasicista en una urbe italiana donde se pueden enumerar más ejemplos de otros palacios renacentistas como los de Francesco Sansovino o Michele Sanmicheli, en la línea arquitectónica palladiana aunque con ciertos matices; los susodichos palacios de Palladio en Venecia, además, no son verídicos. Forman parte de la literatura artística del autor siendo proyectos no llevados a cabo que se recogen en sus Quattro Libri dell'architettura, publicados en Venecia en 1570 y con posteriores reediciones en el siglo XVIII y XIX (Bellavitis, 1982, pp. 55-70).

8 "Tu Venecia, Elíseo del mar, amada de las estrellas, cuyos amplios balcones de los palacios de Palladio, contemplan con profundo y amargo conocimiento los secretos de sus silentes aguas. [...] Fue en Venecia, bajo la arcada cubierta que llaman el Ponte di Sospiri, donde encontré por tercera o cuarta vez a la persona de quien hablo. [...] Venecia estaba extrañamente oscura. El gran reloj de la Piazza había dado la quinta hora de la noche italiana. La plaza del Campanile se mostraba silenciosa y vacía, mientras las luces del viejo Palacio Ducal extinguíanse una tras otra". La traducción se debe a la edición crítica del texto de Julio Cortázar (Poe, 2013, p. 156). 
Después de crear la particular localización espacial comienza a desarrollarse la acción narrativa entre los personajes, donde también hallamos indicaciones a cuestiones relacionadas con las Bellas Artes, destacando dos figuras: Mentoni y la Marquesa Afrodita. Dentro de la primera parte del relato nos interesa ver cómo Poe describe los elementos expresivos de la dama:

She stood alone $[\ldots]$ A snowy-white and gauze-like drapery seemed to be nearly the sole covering to her delicate form; but the mid-summer and midnight air was hot, sullen, and still, and no motion in the statue-like form itself, stirred even the folds of that raiment of very vapor which hung around it as the heavy marble hangs around the Niobe (1978, II, pp. 152-153)9.

Un detalle sustancial lo hallamos en la equiparación de la marquesa con la forma escultórica de Niobe. El propio Mabbot reconoce en las anotaciones del cuento que "The Niobe is a celebrated group at Florence, thought to be a copy of an original by Praxiteles or Scopas" (1978, II, p. 167). Más adelante y con la acción traslada a la residencia de Mentoni, nos vuelve a remitir a un paralelo escultórico construyendo el retrato del personaje masculino:

The person of the stranger [...] The light, almost slender symmetry of his figure, promised more of that ready activity which he evinced at the Bridge of Sighs, than of that Herculean strength which he has been known to wield without an effort, upon occasions of more dangerous emergency. With the mouth and chin of a deity-singular, wild, full, liquid eyes, whose shadows varied from pure hazel to intense and brilliant jet- and a profusion of curling, black hair, from which a forehead of unusual breadth gleamed forth at intervals all light and ivory -his were features than which I have seen none more classically regular, except, perhaps, the marble ones of the Emperor Commodus (1978, II, p. 156) ${ }^{10}$.

9 "La marquesa permanecía sola. [...] Una túnica alba como la nieve y semejante a la gasa parecía ser la única protección de sus delicadas formas; pero el aire estival de aquella medianoche era caliente, denso estático, y aquella imagen estatuaria tampoco hacía el menor movimiento que alterara los pliegues de la vestidura como de vapor que la envolvía, tal como el pesado mármol envuelve la imagen de Níobe" (2013, p. 157).

10 "La persona del desconocido [...] La liviana y esbelta simetría de su figura antes anunciaba la vivaz actividad demostrada en el Puente de los Suspiros, que la hercúlea fuerza que, en ocasiones de mayor peligro, había desplegado sin aparente esfuerzo. Su boca y mentón eran los de una deidad; los ojos, singulares, ardientes, enormes, líquidos, de una tonalidad fluctuando entre el puro castaño y el más intenso y brillante azabache; una profusión de cabello negro y rizado, bajo el cual se destacaba una frente de no común anchura, que por momentos resplandecía como marfil iluminado; tales eran sus rasgos, tan clásicamente regulares que jamás he visto otros semejantes, salvo, quizá, en las imágenes del emperador Cómodo" (2013, p. 159). 
Edgar A. Poe y las artes: el ideario artístico sugerido...-A. Jaquero Esparcia

Tanto la escultura de Niobe como el busto del emperador Cómodo evocan una iconografía propia ligada a los ideales de la Antigüedad clásica ${ }^{11}$. De hecho, la mención del conjunto escultórico de Niobe es más relevante de lo que puede parecer, puesto que conforme la acción del cuento se desarrolle también observaremos menciones al Apolo Belvedere. Estas dos obras formaron parte de las imágenes recurrentes en las ejemplificaciones de los estetas centroeuropeos. El propio Mengs debatió sobre la Niobe y otros ejemplos similares por correspondencia con Monsignor/abad Fabroni, reflexionando acerca de la belleza ideal lograda por los antiguos y su posible recreación a partir de copias más antiguas por autores romanos (Mengs, 1796, I, pp. 44-52). Dichas esculturas representan el punto álgido de lo bello anhelado por la estética neoclásica; un arquetipo de perfección nacido de la observación intelectual de la misma naturaleza, junto a una inclinación a superar el original (Barasch, 1990, pp. 113-121). Algo similar ocurre cuando se especula acerca de las equiparaciones con el rostro de Cómodo. Para Mabbot, esta sugerencia parte del conocimiento de Poe de la historia y numismática antigua (1978, II, 167).

En mi opinión, y tras observar las referencias anteriores, se podría buscar un paralelismo con el busto de Cómodo caracterizado como Hércules, puesto que también se incluye una adjetivación sobre la hercúlea fuerza de aquel. Todas las imágenes escultóricas mencionadas hasta el momento tienen la particularidad de haber conformado el caudal visual de un importante grupo de los artistas que pasaron por Roma y estudiaron la manera de los clásicos, en espacios privilegiados como la loggia o cortile de Belvedere; trabajos que, a su vez, fueron recuperados durante el siglo XVIII para convertirse en arquetipos visuales de la nueva corriente estética que se buscaba instaurar (Ackerman, 1954; Haskell y Penny, 1998, pp. 99-107).

Prosiguiendo con el análisis de la obra y ya en la segunda parte del relato, avanzamos hasta la residencia de Mentoni, lugar donde se producen la mayor parte de las descripciones artísticas y referencias a elementos teórico-artísticos. El protagonista que acompaña al caballero es introducido en un palazzo; el personaje, totalmente obnubilado, describe del siguiente modo dicho espacio: "The eye wandered from object to object, and rested upon none - neither the grotesques of the Greek painters, nor the sculptures of the best Italian days, nor the huge carvings of untutored Egypt" $\left(1978\right.$, II, 157) ${ }^{12}$. El narrador nos explica que cada detalle de la habitación donde ha acompañado al caballero tiene la intención de sorprender y confundir los sentidos. El juicio emitido sobre la colección de Mentoni nos aproxima al gusto de su propietario. Éste, además, es capaz de vanagloriarse del intelecto y buen gusto con los que ha

11 Es más, tal y como apuntan Rigal Aragón y González Moreno en su nuevo estudio sobre las evocaciones pictóricas en la narrativa de Poe, la alusión del emperador Cómodo responde a una relectura ecfrástica de algunos textos clásicos como el de Herodiano de Antioquía en su Historia del imperio romano (s. III d.C.) (Rigal Aragón y González Moreno, 2020, pp. 100-101).

12 "La mirada erraba de objeto a objeto, sin detenerse en ninguno, fueran los grotesques de los pintores griegos, las esculturas de las mejores épocas italianas, o las pesadas tallas del rústico Egipto" (2013, p. 160). 
configurado la arquitectura y ornamentación de su gabinete, dando muestras del alto nivel intelectual heredado del ideario estético surgido en el ambiente academicista. Asimismo, Poe evidencia una ruptura con las predecesoras cámaras de maravillas o gabinetes de curiosidades, que recogían objetos considerados interesantes de índole natural o artística considerándose sólo sus peculiaridades, extravagancias o características religiosas. Hay una evolución espacial reflejada en la modernidad de la estancia y la intencionalidad de la colección (Schlosser, 1988, pp. 7-35). Es por todo ello por lo que el marqués, al ver asombrado a su invitado, se atreve a justificar lo siguiente: "-Here", he resumed arising and leaning on my arm as he sauntered around the apartment, - "here are paintings from the Greeks to Cimabue, and from Cimabue to the present hour" (1978, II, p. 160) $)^{13}$.

El razonamiento nos indica que Poe, a través del discurso del caballero, trata de exponer una periodización artística definida: el origen de las artes representado por el legado griego, marcando el punto de inflexión la pintura de Cimabue -maestro de Giotto-e iniciándose en este momento el auge de los procedimientos prerrenacentistas hasta la época actual ${ }^{14}$. El caballero, por lo tanto, puede presumir en su colección personal de aunar un recorrido antológico de las principales obras y estilos artísticos de la Historia del Arte. Incluso podríamos ir algo más allá: el autor afirma deleitarse con pinturas que, en su mayoría, han desaparecido o se hallan perdidas. Es el caso de la pintura grecolatina, obras que conocemos más por los comentaristas de la Antigüedad que describieron sus beldades que por los ejemplos recuperados (Grassi, 1997, pp. 11-13). En este sentido, Cervantes actúa de manera idéntica en Los trabajos de Persiles y Sigismunda (1617) cuando nos presenta la loggia de Hipólita, decorada con las mejores pinturas de antiguos -Parrasio, Polignoto, Zeuxis, Apeles, Timantes-y modernos -Rafael y Miguel Ángel- (Cervantes, 2004, pp. 669-670).

Poe nos define el perfil intelectual y los criterios estéticos preferentes del propietario aristócrata a través de la descripción de esta colección idealizada. Así, prosigue enumerando las figurillas, pinturas y dibujos que componen la colección, deteniendo su atención en una obra:

Here, too, are some chefs d'œuvre of the unknown great; and here, unfinished designs by men, celebrated in their day, whose very names the perspicacity of the academies has left to silence and to me. What think you," said he, turning abruptly as he spoke -"what think you of this Madonna della Pietà?" -"It is Guido's own!" I said, with

13 "Aquí hay pinturas desde los griegos hasta Cimabue, y de Cimabue hasta la hora actual" (2013, p. 161).

14 Mabbot en su edición del texto específica sobre el pintor italiano que "was the Florentine reviver of painting". Realmente su papel será importante en la evolución del arte pictórico, pero será en el legado de su discípulo Giotto donde se señale realmente esta progresión. Aquí Poe es deudor de las ideas de la historiografía italiana sobre las artes, ya que las principales obras biográficas de artistas integraron a Cimabue como eje vertebrador, de lo que son buen ejemplo de ello los trabajos de Giorgio Vasari y Filippo Baldinucci (Baxandall, 2010, pp. 108-118). 
Edgar A. Poe y las artes: el ideario artístico sugerido...-A. Jaquero Esparcia

all the enthusiasm of my nature, for I had been poring intently over its surpassing loveliness. "It is Guido's own! -how could you have obtained it? she is undoubtedly in painting what the Venus is in sculpture" (1978, II, p.160) ${ }^{15}$.

En un primer instante apreciamos una mera referencia pictórica a la obra de un autor italiano de cierto prestigio en la tradición de la Historia del Arte europeo; a su vez, esta supuesta imagen es equiparada a la clasicista representación escultórica de la Venus. La atención se debe centrar en el primer detalle, la asignación de una autoría concreta a la pintura. Lo que parece una simple cita artística incluida por el autor como recurso literario encierra mayores complejidades, ya que desconocemos si el origen de esta información parte de la lectura de una crónica, de la crítica proveniente de una noticia de prensa o el extracto de alguna de las numerosas lecturas del escritor bostoniano. Ciñéndonos a lo textual, Poe nos aclara la presencia de una pintura ejecutada por el pintor boloñés Guido Reni; los datos proporcionados al respecto, la Madonna della Pietà, nos sugieren las similitudes con la Pietà dei Mendicanti, óleo de considerables dimensiones perteneciente al altar de la iglesia de Santa Maria della Pietà en Boloniay que actualmente se encuentra en el museo de pintura de dicha ciudad (Fig. 1) ${ }^{16}$.

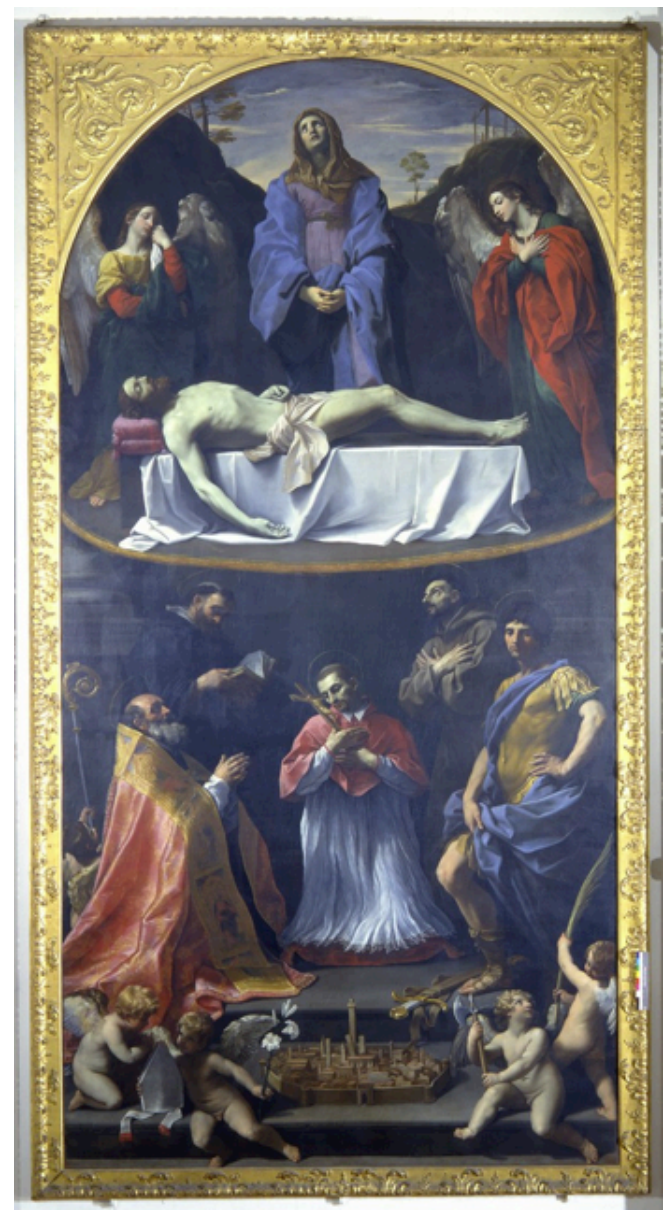

Figura 1: Pietà dei mendicanti, óleo sobre lienzo de Guido Reni, 1613-1616, Pinacoteca Nazionale, Bolonia.

15 "Hay asimismo algunos chefs d'ouvre de grandes desconocidos... y aquí figuran dibujos inconclusos de hombres que fueron celebrados en su día y cuyos nombres han quedado reservados al silencio y a mí, gracias a la perspicacia de las academias. ¿Qué piensa usted-dijo, volviéndose bruscamente mientras hablaba- de esta Madonna della Pietà? -¡Es la obra de Guido! -exclamé con todo el enstusiasmo de mi espíritu, pues había estado contemplando intensamente su incomparable hermosura-. ¡Es la obra de Guido! ¿Cómo pudo usted obtenerla? ¡No cabe duda de que es en pintura lo que la Venus en escultura...!" (2013, p. 161).

16 Las representaciones de la Madonna son frecuentes y variadas en la producción pictórica de Guido Reni, dada la riqueza iconográfica de la imagen. El detalle de referirse a la Pietà hace que no 
La efigie de la virgen fue la que Poe llegó a comparar con la belleza de la escultura de una Venus. El parangón expuesto resulta llamativo, pues la beldad y serenidad de la escultura se contraponen a la expresividad de la pena generada por el rostro de la Madonna. Este matiz se puede deber a que el rostro de la virgen que Poe ha contemplado es diferente al representado por esta pintura de Reni. Las condiciones físicas de la obra impidieron que el escritor bostoniano pudiera tener un contacto visual directo de la misma, por lo que las únicas opciones de que conociese el cuadro fueron a partir de descripciones literarias, copias realizadas al original o, con mayores probabilidades, a través de fuentes gráficas. Asumiendo estas realidades, es necesario plantear otra posibilidad: la existencia de otra Madonna della Pietà de Guido Reni conocida por el escritor, pero con elementos compositivos diferentes. Mabbot señala las incongruencias visuales de la imagen evocada por Poe, advirtiendo de manera oportuna las medidas y disposición real de la obra depositada en Bolonia; también advierte de forma correcta la posibilidad de que el conocimiento del autor sobre la obra provenga de una estampa ${ }^{17}$

El escritor bostoniano buscó transmitirnos la singularidad de dicha obra, tal y como demuestra el énfasis del narrador al percatarse de la espléndida pintura. Así, este hecho podría hallarse justificado de la misma forma que las menciones pictóricas anteriores: se está haciendo referencia a una pintura desaparecida, incluida en la excepcional colección del protagonista. A continuación, se tratará de dar argumentos a esta hipótesis. Las crónicas y posteriores estudios sobre la obra de Reni nos hablan de que dicha pintura existió, si bien es cierto que fue atribuida a otros pintores italianos e incluso al propio taller del boloñés. Conocemos un grabado de Antonio Ricciani Romano en el que aparece una Pietà basada en una pintura de Reni, con una composición diferente a la del cuadro que se conserva en Bolonia (Fig. 2) (Pepper, 1984, p. 231).

La estampa, acompañada de una descripción en latín sobre la escena y una dedicatoria al religioso Carlo Odescalchi, contiene la inscripción ideavit Guido Reni, lo que indica la dependencia con la obra del artista boloñés. Las firmas del aguafuerte dejan claro que la obra fue diseñada por Agostino Tofanelli y grabada por Romano, partiendo de una pintura de Reni incluida en la colección de Domenico Venuti, caballero italiano que ejerció como superintendente del Real Museo Borbónico de Nápoles durante el siglo XVIII. Resulta curioso observar el papel destacado de Venuti en la recuperación de las colecciones artísticas, sobre todo de pinturas, sustraídas por las tropas francesas durante la invasión del siglo XIX, aunque no llegaría a completar esta recuperación (Strazzullo, 1991-1992, pp. 13-62). Aquí perdemos

la debamos confundir con otras producciones del pintor. Sobre la obra, iconografía trabajada e ideario artístico de Reni (Baccheschi, 1977, pp. 84-85; Emiliani, 1988, pp. 17-103).

17 "His Madonna is a masterpiece of Guido Reni (1575-1642) now in the Gallery of his native Bologna. It is very large, over ten by twenty feet. Poe probably knew it from an engraving, and may have been unaware of its size" (1978, II, p. 168). 
Edgar A. Poe y las artes: el ideario artístico sugerido...-A. Jaquero Esparcia

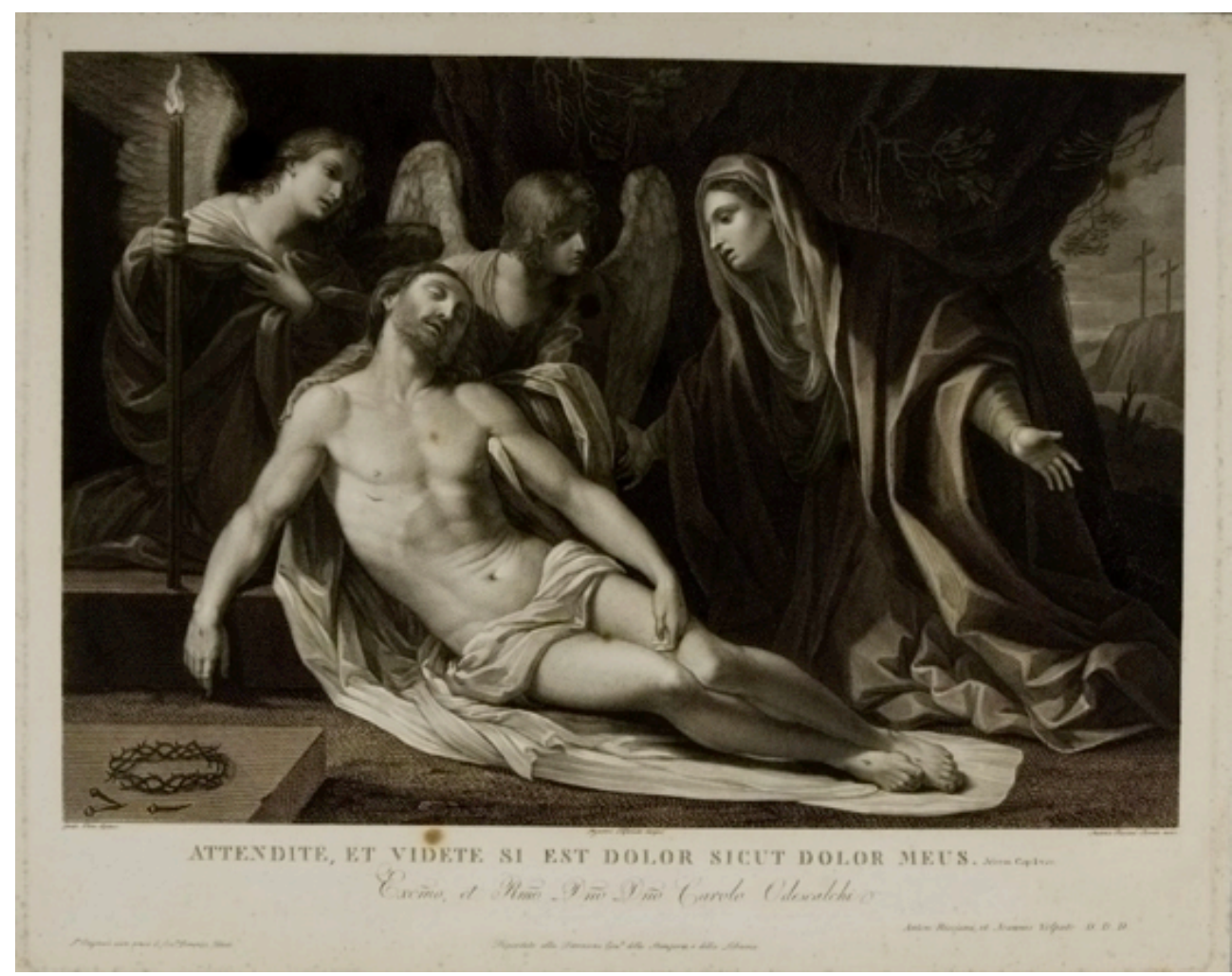

Figura 2: Antonio Ricciani. Pietà, agufuerte de Antonio Ricciani Romano, 1795-1814. Aguafuerte, British Museum, Londres.

el rastro del cuadro de Guido Reni. Si continuamos rastreando la fortuna de la obra encontraremos copias atribuidas a la pintura de Reni en la colección pictórica de la York Art Gallery, en la capilla católica del Etton College o la que fue vendida por Sothebys con la descripción The Lamentation; obras de dudosa atribución pero que repiten esta composición perdida ${ }^{18}$. Lo que es cierto es que detrás de la obra referida por el escritor de Boston surgen incógnitas que solamente pueden ser conocidas a través de la literatura artística de la época o bien partiendo de los datos inscritos en el material gráfico. El recurso literario con el que juega Poe, por lo tanto, es el mismo que presentó Cervantes en el Persiles: la idealización de un espacio para albergar una pintura en cierto modo desaparecida y singular.

18 La obra depositada en la York Art Gallery fue atribuida por estudiosos como Denis Mahon al taller de los Carracci, sin desligarse totalmente la dependencia de Reni; la pintura del Etton College fue atribuida finalmente por Pepper a Pietro Testa; y la descripción adjunta al cuadro vendido en Sothebys fue: "This composition récords the appearance of a lost painting by Guido Reni, known through an $18^{\text {th }}$ -century engraving by Antonio Ricciani Romano, following a drawing by Agostino Tofanelli after the original painting" (Pepper, 1984, p. 251; VV.AA., 2009, p. 26). 
La acción del texto no se detiene aquí, sino que retoma las referencias artísticas partiendo de la equiparación de la Madonna de Guido con la Venus de Médici, momento en el cual Mentoni procede a especular, nuevamente, sobre escultura clásica:

"Ha!" said he, thoughtfully, "the Venus -the beautiful Venus?-the Venus of the Medici?she of the diminutive head and the gilded hair? Part of the left arm (here his voice dropped so as to be heard with difficulty, and all the right, are restorations; and in the coquetry of that right arm lies, I think, the quintessence of all affectation (1978, II, p. 160) ${ }^{19}$.

El barón explica sus impresiones de la escultura que hoy en día se encuentra en la Galleria degli Uffizi. Elabora un comentario de los brazos a los que atribuye unas características estéticas que acentúan el valor de la obra. A propósito de las extremidades, habían sido restauradas por Ercole Ferrata durante el siglo XVII, motivo por el cual recibiría algunas críticas (Haskell y Penny, 1998, pp. 325-328). La Venus, además, había sido referida con anterioridad por Lord Byron y suponía una visita obligada para los viajeros europeos decimonónicos. Cuando Poe afirma por medio de los comentarios del barón el placer que le supone la contemplación de estas piezas restauradas, reconoce que las copias o remodelaciones logradas por la intervención del ser humano tienen en sí mismas un grado de belleza. Una circunstancia que no se detiene aquí, prefiriendo el barón otros modelos: "Give me the Canoval! The Apollo, too, is a copy - there can be no doubt of it - blind fool that I am, who cannot behold the boasted inspiration of the Apollo! I cannot help - pity me! - I cannot help preferring the Antinous" (1978, II, p. 160) ${ }^{20}$.

A partir de aquí se inicia un breve alegato cargado de referencias a la estatuaria clásica y moderna. Las menciones a las copias de Apolo y Antínoo nos vuelven a conectar con las evocaciones a la estatuaria clásica iniciadas al comienzo de la narración, aunque la atención se focaliza en otra obra singular. El narrador comienza recuperando entre sus predilecciones la escultura de Venus elaborada por el escultor y pintor neoclásico Antonio Canova. Con esta mención, anteponiéndola a la otra Venus, posiciona el perfil del coleccionista a favor de la evolución estética winckelmaniana propuesta por el escultor italiano, un nuevo Bernini que bebe de la tradición escultórica grecolatina. Mabbot señala en sus apuntes al texto, además de la autoría y cronología de la obra, que la Venus mencionada por Poe "is really a nude portrait of Pauline Bonaparte, riding on a lion's back" (1978, II, p. 168). Para el académico norteamericano se está mencionando una escultura específica

19 “-¡Ah! - dijo pensativamente-. Venus..., la hermosa Venus... ¿La Venus de Médicis? ¿La de la pequeña cabeza y el resplandeciente cabello? Parte del brazo izquierdo -aquí su voz se tornó tan baja que me costó oírla- y todo el derecho han sido restaurados; pienso que en la coquetería de ese brazo derecho reside la quintaesencia de la afectación” (2013, p. 161).

20 “¡Para mí la Venus de Cánova! El mismo Apolo es una copia..., no cabe la menor duda... ¡Oh, estúpido y ciego que soy, incapaz de alcanzar la tan mentada inspiración del Apolo! Perdóneme usted, pero no puedo evitar..., ¡téngame lástima!..., una preferencia por el Antínoo" (2013, pp. 161-162). 
de Canova, la Venus Victrix, localizada en la Galeria Borghese e inspirada en la aristócrata hermana de Napoleón, Pauline Bonaparte. En cambio, quizá no sea ésta la escultura a la que Poe se refería. La narración antecedente nos habla de una escultura de bulto redondo y alzada, mientras que el ejemplo de Mabbot presenta una estatua yacente, recostada sobre un lecho, con unas connotaciones históricas a las que en ningún momento se alude en el texto. En la trayectoria artística de Canova se pueden enumerar otras reinterpretaciones de Venus; la Venus itálica estaría más cercana a la idea de Poe. Localizada durante el siglo XIX en la Galleria Imperiale de Florencia, hoy en día se halla en el Palacio Pitti. En su momento fue considerada un hito que buscó superar la belleza de esta antigua copia romana (Honour, 1972, pp. 658671). Asimismo, se generaron diversas estampas de la obra, como las de Domenico Marchetti, y testimonios literarios accesibles en los Estados Unidos.

Tratando de clarificar el discurso artístico que Poe propone, se puede observar cómo buscó exponer una apología de los modelos estéticos neoclásicos. El trabajo de Antonio Canova representaba la evolución con respecto al pasado inmediato sustentada en los ideales de la Antigüedad clásica. El artista italiano supo extraer las cotas más altas de belleza a través de la estatuaria clásica y la correcta observación de la naturaleza, alineándose con los postulados defendidos por los grandes estetas neoclásicos (Micheli, 2003, pp. 277-299). Es más, el propio Poe pudo sentirse identificado con esta actitud, puesto que también acude a los literatos clásicos con el fin de hallar modelos para sus escritos (González-Rivas Fernández, 2010, pp. 413459; Tsokanos, 2017, 169-180). En esta misma línea, la disputa en torno a las copias o las restauraciones contemporáneas puede abrir nuevos puntos de controversia dentro del debate entre lo antiguo y lo moderno; tanto el Antínoo como el Apolo son copias de mármol de obras griegas pretéritas elaboradas en bronce. Emitiendo un dictamen final sobre este asunto, el narrador sentencia: "Was it not Socrates who said that the statuary found his statue in the block of marble? Then Michæl Angelo was by no means original in his couplet - "Non ha l'ottimo artista alcun concetto / Che un marmo solo in se non circonscriva" (1978, II, pp. 160-161) ${ }^{21}$.

Estas dos afirmaciones ponen de manifiesto la posición de Poe a propósito del concepto de invención en la creación artística. Por un lado, alude a una cita atribuida a Sócrates. El comentario del filósofo griego fue recogido por Diógenes Laercio en sus Vidas y opiniones de los filósofos ilustres, donde se puede leer: "decía que se asombraba de que quienes esculpían las estatuas atendieran en sus proyectos a que la piedra se pareciera al máximo (a un ser humano), mientras que se desatendían a sí mismos en no mostrarse semejantes a la piedra" (Diógenes Laercio, 2007, p. 105). En este caso la sentencia del filósofo no reflexiona tanto sobre el concepto de idea artística como de la propia actitud del artista, aportando una lección moral.

21 “No fue Sócrates quien afirmó que el escultor encuentra su estatua en el bloque de mármol? En ese caso, Miguel Ángel no se encontró nada original en sus versos: Non ha l'ottimo artista alcun concetto / Che un marmo solo in se non circonscriva" (2013, p. 162). 
Por otro, uno de los sonetos de Miguel Ángel Buonarroti. Una cita poética relevante, ya que nos expone uno de los pocos textos conservados por el artista florentino y, en algunos casos, una mínima presentación de su ideario artístico (Clements, 1965, pp. 60-88). El soneto defiende la labor intelectual del escultor, el cual construye en su mente la obra que va a trasladar al mármol (Buonarroti, 2015, pp. 324-325). La idea, concebida por Miguel Ángel desde una perspectiva neoplatónica, habita en la mente del escultor; ese concetto será el que le lleve a configurar cualquier bloque de mármol, entendido éste como espacio en blanco donde desarrollar la labor artístico-creadora bajo sus propias motivaciones (Panofsky, 2013, pp. 123-136). La reflexión de Sócrates unida a los versos de Miguel Ángel, en suma, complementan una estimación hacia el rol del artífice en la obra de arte, capaz mediante su criterio de trasladar su pensamiento, la idea, a la creación artística. En unas pocas líneas se llega a especular sobre el valor de la idea en la obra artística y, por lo tanto, en la defensa del genio creador heredada de la Antigüedad clásica y reformulada en el Renacimiento (Kris y Kurz, 2010, pp. 52-60). Estas afirmaciones entroncan con las preferencias del marqués, el cual alaba las obras de Canova y las copias surgidas de la imitación idealizada de la belleza clásica.

Después del largo discurso en torno a la escultura y el concepto de idea y genio artístico, el diálogo mantenido por los dos protagonistas del relato se aparta de estas constantes referencias al mundo clásico de las artes. Una mención a las cornisas de los templos de Persépolis será de las pocas alusiones que encontraremos junto al detalle de dos piezas de cerámica etrusca ${ }^{22}$. El narrador del cuento, tras todo lo acontecido y debatido con su interlocutor, es consciente del alto nivel cultural del marqués y de su formación intelectual, en la línea de, como termina citando, un gentleman. Ratifica esta opinión tras leer unos versos compuestos por el marqués en lengua inglesa. Un suceso que conecta con la que es la última referencia a un elemento artístico. El marqués advierte a su invitado de que hay una obra en la sala en la cual todavía no ha reparado:

"There is one painting," said he, without being aware of my notice of the tragedy "there is still one painting which you have not seen." And throwing aside a drapery, he discovered a full-length portrait of the Marchesa Aphrodite. Human art could have done no more in the delineation of her superhuman beauty. The same ethereal figure which stood before me the preceding night upon the steps of the Ducal Palace [...] But in the expression of the countenance, which was beaming all over with smiles, there

22 Mabbot ha señalado que las citas a los elementos arquitectónicos orientales se encuentran vinculadas con los conceptos desarrollados en el poema "Al Aaraaf" o la acción del cuento "Silencio (Fábula)” desarrollada en Baalbek (1978, I, pp. 107 y 121; II, p. 169). En cuanto a la cerámica etrusca citada por Poe, algunos investigadores han llegado a especular que se halla relacionada con una colección estadounidense que llegó a comienzos del siglo XIX (Ramage y Cromey, 2013, pp. 169-180). 
Edgar A. Poe y las artes: el ideario artístico sugerido...-A. Jaquero Esparcia

still lurked (incomprehensible anomaly!) that fitful stain of melancholy which will ever be found inseparable from the perfection of the beautiful (1978, II, p. 164) ${ }^{23}$.

El ejercicio descriptivo narrado por Poe trata de sintetizar todas las sugerencias estéticas recogidas en el texto focalizándolas en el óleo imaginario de su amada Marquesa Afrodita; la obra es el culmen de la belleza, haciendo honor a la perfección que simboliza. En ella vive representada el principal amor del marqués, pero hay algo más. Si nos ceñimos al retrato literario advertimos que esta pintura reúne las principales características que han ido siendo referidas a lo largo de todo el cuento. En cierto sentido, la pintura representa el arquetipo pictórico de todos los ideales estéticos neoclásicos expuestos con anterioridad. Solamente una pintura imaginaria podría ser la que aglutine los valores resumidos de la colección artística del personaje: una combinación de elementos de un caballero amante de las artes, imbuido del espíritu neoclásico generado a través de los razonamientos de los pensadores ya citados a lo largo de estas líneas. Después de la visualización de este retrato comienza el monólogo final de Mentoni, donde reconoce un hecho trascendental de la narración: "To dream has been the business of my life. I have therefore framed for myself, as you see, a bower of dreams" (1978, II, p. 165) ${ }^{24}$.

El pintoresco gabinete de las artes se halla integrado por singulares obras artísticas de principales maestros, elementos suntuosos y demás excentricidades fastuosas habituales en el ideario manejado por los aristócratas del siglo XIX; sin embargo, el espacio descrito es una visión idealizada que recoge obras ilocalizables, imaginarias o visitables a través de los correspondientes viajes a las localidades donde se encontraban, fomentando la cultura del Grand Tour en un espacio como Venecia, punto de obligada visita en estos viajes formativos (Redford, 1996, pp. $15-21)^{25}$.

23 "- Hay una pintura - dijo él, sin advertir que yo había estado leyendo la tragedia- que todavía no ha visto usted. Y, apartando una colgadura, descubrió un retrato de tamaño natural de la marquesa Afrodita. El arte humano no podía haber hecho más en el trazado de su belleza sobrehumana. La misma etérea figura que se alzaba ante mí la noche anterior en la escalinata del Palacio Ducal volvía a ofrecerse a mis ojos. Pero en la expresión de su rostro, que resplandecía sonriente, se insinuaba -jincomprensible anomalía!- esa incierta mácula de melancolía que siempre será inseparable de la perfección de la hermosura" (2013, p. 164).

24 "-Soñar -continuó, recobrando el tono de su inconexa conversación-, soñar ha constituido el fin de mi vida. Por eso he construido, como ve usted, este lugar para los sueños" (2013, p. 165).

25 El establecimiento del viaje cultural por Europa promovió una numerosa cantidad de movimientos con fines formativos y culturales por parte de algunos colectivos aristócratas, promoviendo la educación de sus hijos. Además, generó una nutrida literatura de viajes que enriqueció la literatura artística del momento gracias a sus interesantes descripciones y críticas sobre las obras de arte. Buen ejemplo de ello es el libro de Mariana Starke Travels on the Continent: Written for the Use and Particular Information of Travellers (1820), basados muchos de los relatos en sus Letters from Italy, between the years 1792 and 1798 (1800) (Sweet, 2012, pp. 11-12 y 106-107). 


\section{GONCLUSIONES}

Después de haber confrontado el breve texto de Edgar Allan Poe con las principales ideas de la teoría de las artes y estéticas de su época, las correspondencias existentes nos permiten advertir, al menos, más de una analogía. En "The Assignation", además del desarrollo de la trama literaria creada por el autor, observamos la construcción de un perfil claro del caballero intelectual amante de las Bellas Artes, en la línea de muchos getlemen o virtuosi decimonónicos. A través de las múltiples reflexiones y observaciones que van introduciéndose de manera paulatina en el texto, el escritor erige un ambiente espacial y un nivel estético que le muestra como un conocedor de la literatura artística y de la crítica de arte europea. Muchas de las referencias a las que se alude a lo largo del texto solamente se adquieren tras el contacto con esta bibliografía específica, por lo que debió de producirse un acercamiento a dichos textos. Del mismo modo, el caudal visual del que hace gala, es decir, su conocimiento de obras de arte y diversas composiciones, también es sólido. La mayoría de las referencias artísticas descritas o sugeridas parten de un dominio de materiales gráficos como estampas o revistas románticas profusamente ilustradas con grabados xilográficos, las cuales proporcionan un rico panorama artístico imposible de ser visionado y adquirido de otra forma.

A lo largo de toda la narración Poe consiguió elaborar una evolucionada construcción de la arquetípica narración romántica del caballero amante de las artes, deudora de otros autores como Lord Byron o Percy Bysshe Shelley. Consiguió acercar a los lectores, sobre todo a aquellos más instruidos en la cultura históricoartística europea, un modelo definido de coleccionista romántico; amante de las artes y conocedor de las ideas fundamentales que las originan y revalorizan. Es más, llegó a ahondar en aspectos propios de la Historia del Arte sobre pinturas o esculturas más propios de los connoisseur o especialistas. Dicha particularidad la observamos en las conjeturas generadas en torno a la pintoresca colección de Mentoni: un conjunto de piezas que, por su fortuna y características históricas, jamás pudieron hallarse reunidas en un mismo espacio; obras particulares cuyo único modo de verse localizadas en un mismo espacio era a través de las elucubraciones y fantasías de un erudito. Las pinturas de griegos o romanos, las esculturas medievales de Italia y el mismo cuadro de Guido Reni, son una perfecta representación de ello. A propósito de esta última obra, el cuadro de Reni enriquece todo este constructo, siendo algo más que una alusión artística. Bajo la óptica romántica que se plasmó en todo el texto, se rememoró el recurso literario utilizado por anteriores escritores en el que se nos describen obras singularísimas, extrañas y desaparecidas, con la intencionalidad de mostrar una mayor excepcionalidad de toda la colección. Del mismo modo que hicieran antes otros grandes escritores amantes de las Bellas Artes en el ambiente literario europeo, Poe prosigue con esta serie de reminiscencias.

La relectura pausada y detallada de la literatura poeniana nos muestra la complejidad intelectual de su artífice, superando los obsoletos juicios de valor 
Edgar A. Poe y las artes: el ideario artístico sugerido...-A. Jaquero Esparcia

versados sobre su personalidad alcoholizada y poco menos que la de un sujeto que debía el valor de su obra a los diversos estados alterados de conciencia y espíritu. Asimismo, la obra que hemos expuesto en estas líneas nos muestra el bagaje intelectual del escritor y las inquietudes artísticas profesadas, las cuales también son visibles en otros lugares de su extensa obra. Por ahora, se aportan nuevas herramientas de análisis para comprobar la profundidad literaria y el vasto caudal histórico-artístico presentes en "The Assignation".

\section{BIBLIOGRAFÍA}

Ackerman, James S. (1954). The cortile del Belvedere. Ciudad del Vaticano: Biblioteca Apostólica Vaticana.

Antal, Frederick (1989). Estudios sobre Fuseli. Ed. Carlos Manzano. Madrid: Visor.

Ashfield, Andrew y Bolla, Peter de (1996). The Sublime: A Reader in British EighteenthCentury Aesthetic Theory. Cambridge: Cambridge University Press.

Baccheschi, Edi (1977). La obra pictórica completa de Guido Reni. Barcelona: Noguer.

Barasch, Moshe (1990). Theories of Art. From Winckelmann to Baudelaire. New YorkLondon: Routledge.

Barrell, John (1986). The Political Theory of Painting from Reynolds to Hazlitt: The Body of the Public. New Haven-London: Yale University Press.

Baxandall, Michelle (2010). Giotto y los oradores. La visión de la pintura en los humanistas italianos y el descubrimiento de la composición pictórica (1350-1450). Madrid: Antonio Machado Libros.

Beddington, Charles y Bradley, Amanda (2010). Venice Canaletto and his rivals. London: Yale University Press.

Bellavitis, Giorgio (1982). I progetti di palladio per due palazzi a Venezia, en Puppi, Lionello (ed.). Palladio e Venezia. Firenze: Sansoni Editore, pp. 55-70.

Benton, Richard P. (1963). Is Poe's "The Assignation” A Hoax?. Nineteenth-Century Fiction, n. 18 (2), pp. 193-197.

Bozal, Valeriano (2011). Historia de las ideas estéticas y de las teorías artísticas contemporáneas. Madrid: Antonio Machado Libros.

Buonarroti, Michelangelo (2015). Rime. Ed. Paolo Zaja. Milano: BUR Rizzoli.

Campbell, Killis (1925). Poe's Reading. University of Texas Studies in English, n. 5, pp. 166-196.

Cantalupo, Barbara (2014). Poe and the Visual Arts. Pennsylvania: The Pennsylvania State University Press.

Cervantes, Miguel de (2004). Los trabajos de Persiles y Sigismunda. Historia Septentrional. Ed. Carlos Romero Muñoz. Madrid: Cátedra. 
Clements, Robert J. (1965). The Poetry of Michelangelo. New York: New York University Press.

Crespo Delgado, Daniel. 2015. Lectores y noticias sobre bellas artes en los papeles periódicos españoles de la Ilustración. En por Maestre Maestre, José María, Díaz Gito, Manuel Antonio y Romero Ferrer, Alberto (eds.). Francisco Mariano Nipho. El nacimiento de la prensa y de la crítica literaria periodística en la España del siglo XVIII. Madrid: Instituto de Estudios Humanísticos, CSIC, pp. 199-215.

D’Evelin, Margaret M. (2012). Venice \& Vitruvius: reading Venice with Daniele Barbaro and Andrea Palladio. New Haven: Yale University Press.

De Armas, Frederick (2006). Quixotic frescoes: Cervantes and Italian Renaissance. Toronto: University of Toronto Press.

Démoris, René y Ferran, Florence (2001). Le peinture en procès. L'invention de la critique d'art au siècle des Lumières. Paris: Presses Sorbonne Nouvelle.

Diógenes Laercio (2007). Vidas y opiniones de los filósofos ilustres. Ed. Carlos García Gual. Madrid: Alianza.

Duro, Paul (2002). Academic Theory 1550-1800. En Smith, Paul y Wilde, Carolyn (eds.). A Companion to Art Theory. Oxford: Blackwell Publishing, pp. 88-103.

Emiliani, Andrea (1988). La vita, i simboli e la fortuna di Guido Reni. En Mahon, Denis et. Al. (coord.). Guido Reni. 1575-1642 (catálogo de la exposición realizada en Bolonia, Los Ángeles y Fort Worth). Bologna: Nuova Alfa Ed., 1988, pp. 17-103.

Fried, Michael (1986). Antiquity Now: Reading Winckelmann on Imitation. The MIT Press, n. 37, pp. 87-97.

González Moreno, Beatriz (2007). Lo sublime, lo gótico y lo romántico: la experiencia estética del romanticismo inglés. Cuenca: Universidad de Castilla-La Mancha.

González Moreno, Fernando y Rigal Aragón, Margarita (2018). Poe and the Art of Painting: Tales to Be Seen - the First Spanish Illustrated Edition. The Edgar Allan Poe Review, n. 19 (1), pp. 7-27.

González-Rivas Fernández, Ana (2009). "The Assignation": An Aesthetic Encounter of Classical and Gothic. The Edgar Allan Poe Review, n. 10 (1), pp. 50-62.

González-Rivas Fernández, Ana (2010). Los clásicos grecolatinos y la novela gótica angloamericana: encuentros complejos. Madrid: Servicio de Publicaciones de la Universidad Complutense.

Grassi, Luigi (1997). Teorici e Storia della Critica d'Arte. Il Settecento in Italia. Roma: Bonsignori Editore.

Griggs, Earl L. (1929). Five Sources of Edgar Allan Poe's Pinakidia. American Literature, n. 1 (2), pp. 196-199.

Groseclose, Barbara (2000). Nineteenth-Century American Art. Oxford: Oxford University Press. 
Edgar A. Poe y las artes: el ideario artístico sugerido...-A. Jaquero Esparcia

Hagstrum, Jean H. (1958). The Sister Arts. The Tradition of Literary Pictorialism and English Poetry from Dryden to Gray. London: The University of Chicago Press.

Haskell, Francis y Penny, Nicholas (1998). Taste and the Antique. The Lure of Classical Sculpture 1500-1900. New Haven-London: Yale University Press.

Honour, Hugh (1972). Canova's Statues of Venus. The Burlington Magazine, n. 114 (835), pp. 658-671.

Houghton, Walter E. Jr. (1942). The English Virtuoso in the Seventeenth Century: Part II. Journal of the History of Ideas, n. 3 (2), pp. 190-219.

Kris, Erns y Kurz, Otto (2010). La leyenda del artista. Madrid: Cátedra.

Levi, Donata (2010). Il discorso sull'arte. Dalla tarda antichità a Ghiberti. MilanoTorino: Bruno Mondadori.

Mengs, Anton Raphael (1796). The Works of Anthony Raphael Mengs, First Painter to his Catholic Majesty Charles III. London: R. Faulder.

Mengs, Anton Raphael (1989). Reflexiones sobre la Belleza y Gusto en la Pintura. Ed. Mercedes Agueda. Madrid: Instituto de Conservación y Restauración de Bienes Culturales, Colegio Oficial de Aparejadores y Arquitectos Técnicos.

Micheli, Maria (2003). Iudicium et ordo: Antonio Canova and Antiquity. En Fejfer, Jane, Fischer-Hansen, Tobias y Rathje, Annette (eds.). The Rediscovery of Antiquity: The Role of the Artist. Gylling: Museum Tusculanum Press-University of Copenhagen, pp. 277-299.

Miyazawa, Naomi (2017). Poe, the Portrait, and the Daguerreotype: Poe's Living Dead and the Visual Arts. Poe Studies, n. 50, pp. 88-106.

Mongtgomery, Travis (2010). Poe's Oriental Gothic: "Metzengerstein" (1832), "The Visionary" (1834), "Berenice" (1835), the "Imagination", and Authorship's Perils. Gothic Studies, n. 12 (2), pp. 4-28.

Moreland, Clark y Rodríguez, Karime (2015). "Never Bet the Devil Your Head": Fuseli’s The Nightmare and Collapsing Masculinity in Poe's "The Black Cat". The Edgar Allan Poe Review, n. 16 (2), pp. 204-220.

Pahl, Dennis (1984). Recoveryng Byron: Poe's “The Assignation”. Criticism, n. 26 (3), pp. 211-229.

Pahl, Dennis (2006). "Poe's Sublimity: The Role of Burkean Aesthetics". The Edgar Allan Poe Review, n. 7 (2), pp. 30-49.

Panofsky, Erwin (2013). Idea. Contribución a la historia de la teoría del arte. Madrid: Cátedra.

Pelzel, Thomas (1976). Anton Raphael Mengs and His British Critics. Studies in Romanticism, n. 15 (3), pp. 425-421.

Pepper, Stephen C. (1984). Guido Reni: a complete catalogue of his works. Oxford: Phaidon. 
Perosa, Sergio (1999). Literary Deaths in Venice. En Pfister, Manfred y Schaff, Barbara

(eds.). Venetian Views, Venetian Blinds. English Fantasies of Venice. Amsterdam: Rodopi, pp. 115-128.

Pevsner, Nikolaus (1982). Las academias de arte. Pasado y presente. Madrid: Cátedra.

Pierson, William H. Jr. (1970). American Buildings and their Architects: The Colonial and Neo-Classical Styles. Garden City: Anchor Press, Doubleday.

Pitcher, Edward W. (1980). Poe's “The Assignation”: A Reconsideration. Poe Studies, n. 13, pp. 1-4.

Poe, Edgar Allan (1978). The Visionary (The Assignation). En Mabbott, Thomas Ollivet (ed.). The Collected Works of Edgar Allan Poe - Vol. II: Tales and Sketches. Cambridge: The Belknap Press of Harvard University Press, II, pp. 148-169.

Poe, Edgar Allan (2013). Narrativa completa. Ed. Margarita Rigal Aragón. Madrid: Cátedra.

Quinn, Arthur H. (1998). Edgar Allan Poe: A Critical Biography. Baltimore: Johns Hopkins Paperbacks.

Ramage, Nancy Hirschl y Cromey, Robert David (2013). Two "Etruscan" Vases and Edgar Allan Poe. Metropolitan Museum Journal, n. 48, pp. 169-180.

Redford, Bruce (1996). Venice and the Grand Tour. New Haven: Yale University Press.

Rigal Aragón, Margarita y González Moreno, Fernando (2019). The Pictorial Richness of Poe's Oeuvre. En González Moreno, Beatriz y González Moreno, Fernando (eds.). Painting Words. Aesthetics and the Relationship between Image and Text.). London: Routledge, 2020, pp. 93-112.

Rodríguez Guerrero-Strachan, Santiago (2010). Poe`s Poetry: Melancholy and the Picturesque. En González Moreno, Beatriz y Rigal Aragón, Margarita (eds.) A Descent into Edgar Allan Poe and His Works: The Bicentennial. Bern: Peter Lang, pp. 97-106.

Salerno, Luigi (1951). Seventeenth-Century English Literature on Painting. Journal of the Warburg and Courtauld Institutes, n. 14 (3/4), pp. 234-258.

Saltz, Laura (2006). Eyes which Behold: Poe's "Domain of Arheim" and the Science of Vision. The Edgar Allan Poe Review, n. 7 (1), pp. 4-30.

Savoye, Jeffrey A. (2013). Tintoretto and "The Oval Portrait". The Edgar Allan Poe Review, n. 14 (2), pp. 233-234.

Schlosser, Julius von (1988). Las cámaras artísticas y maravillosas del renacimiento tardio: una contribución a la historia del coleccionismo. Madrid: Akal.

Solkin, David H. (2001). Art on the Line: The Royal Academy Exhibitions at Somerset House 1780-1836. New Haven: University Press for the Paul Mellon Centre for Studies in British Art and the Courtauld Institute Gallery. 
Edgar A. Poe y las artes: el ideario artístico sugerido...-A. Jaquero Esparcia

Strazzullo, Franco (1991-1992). Domenico Venuti e il ricupero delle opere d'arte trafugate dai francesi a Napoli nel 1799. Rendiconti della Accademia di Archeologia, Lettere e Belle Arti, n. 63, pp. 13-62.

Sweet, Rosemary (2012). Cities and the Grand Tour. The British in Italy, c. 1690-1820. New York: Cambridge University Press.

Thorp, Margaret F. (1931). "Shakespeare and the Fine Arts". PMLA, n. 46 (3), pp. $672-$ 693.

Tsokanos, Dimitrios (2017). Hellenic Language and Literature in Poe's Horror Short Stories: "Siope- A Fable" and "The Sphinx". The Grove. Working Papers on English Studies, n. 24, pp. 169-180.

VV.AA. (2009). Old Master \& Early British Paintings. Auction in London Thursday 30 October 2008. London: Sotheby's.

Watson, Francis John. B. (1950). Notes on Canaletto and His Engravers-I. The Burlington Magazine, n. 92 (571), pp. 290-293. 